\title{
Agricultura familiar e alimentação escolar: reflexos da pandemia de COVID-19
}

\author{
Family farming and school feeding: reflections of the COVID-19 pandemic \\ Agricultura familiar y alimentación escolar: reflejos de la pandemia COVID-19
}

\author{
Genyvana Criscya Garcia Carvalho \\ ORCID: https://orcid.org/0000-0002-8151-8746 \\ Universidade Paulista, Brasil \\ E-mail: genyvanacarvalho@icloud.com \\ Ivonalda Brito de Almeida Morais \\ ORCID: https://orcid.org/0000-0002-1306-7568 \\ Universidade Paulista, Brasil \\ E-mail: ivonaldaa@gmail.com.br \\ Guilherme Antônio Lopes de Oliveira \\ ORCID: https://orcid.org/0000-0003-3820-0502 \\ Christus Faculdade do Piauí, Brasil \\ E-mail: guilhermelopes@live.com \\ Oduvaldo Vendrametto \\ ORCID: https://orcid.org/0000-0003-2430-6138 \\ Universidade Paulista, Brasil \\ E-mail: oduvaldov@gmail.com
}

\begin{abstract}
Resumo
O isolamento social tem sido uma medida importante para conter a pandemia causada pela COVID-19. Diante desse contexto, as escolas tiveram que suspender as aulas e consequentemente e o Programa Nacional de Alimentação Escolar (PNAE) sofreu um grande impacto, gerando muitos desafios para dar continuidade ao programa dentro de um cenário pandêmico. Diversas normativas foram criadas para minimizar os impactos negativos, como por exemplo a autorização da distribuição de gêneros alimentícios adquiridos no âmbito do PNAE aos responsáveis pelos estudantes durante a pandemia. Um setor bastante afetado foi a agricultura familiar que tem o PNAE como principal consumidor dos seus produtos. Com as aulas suspensas, a situação ficou bem complexa. O objetivo desse estudo é discutir os desafios para execução do PNAE em relação à compra da agricultura familiar durante a pandemia pela Covid-19. Foi realizada uma pesquisa bibliográfica com base em fontes documentais e bibliográficas, de março de 2020 a fevereiro de 2021, referentes ao PNAE e agricultura familiar. A pandemia pelo Covid-19 trouxe novos desafios, que devem ser discutidos e superados, por meio de ações que garantam apoio aos agricultores, com o fito de diminuir os efeitos da pandemia.
\end{abstract}

Palavras-chave: Agricultura familiar; Alimentação escolar; COVID-19.

\begin{abstract}
Social isolation has been an important measure to contain the pandemic caused by COVID-19. Given this context, schools had to suspend classes and consequently and the National School Meals Program (PNAE) suffered a major impact, generating many challenges to continue the program within a pandemic scenario. Several regulations were regulated to reduce the impacts issued, such as the authorization of the distribution of foodstuffs acquired under the PNAE to those responsible for students during the pandemic. A very affected sector was family farming, whose PNAE is the main consumer of its products. With classes suspended, the situation became very complex. The purpose of this study is to discuss the challenges for implementing the PNAE in relation to the purchase of family farming during a pandemic by Covid-19. A bibliographic search was carried out based on documentary and bibliographic sources, from March 2020 to February 2021, referring to PNAE and family farming. The Covid-19 pandemic brought new challenges, which must be discussed and overcome, through actions that guarantee support to farmers, with the aim of reducing the effects of the pandemic.
\end{abstract}

Keywords: Family farming; School feeding; COVID-19.

\section{Resumen}

El aislamiento social ha sido una medida importante para contener la pandemia causada por COVID-19. Ante este contexto, las escuelas tuvieron que suspender las clases y en consecuencia y el Programa Nacional de Alimentación Escolar (PNAE) sufrió un gran impacto, generando muchos desafíos para continuar el programa en un escenario de pandemia. Se han creado varias normativas para minimizar los impactos negativos, como la autorización de la distribución de alimentos adquiridos bajo el PNAE a los responsables de estudiantes durante la pandemia. Un sector 
muy afectado fue la agricultura familiar, que tiene al PNAE como principal consumidor de sus productos. Con las clases suspendidas, la situación se volvió muy compleja. El objetivo de este estudio es discutir los desafíos para la implementación del PNAE en relación a la compra de agricultura familiar durante la pandemia por Covid-19. Se realizó una búsqueda bibliográfica a partir de fuentes documentales y bibliográficas, desde marzo de 2020 hasta febrero de 2021, referida al PNAE y la agricultura familiar. La pandemia Covid-19 trajo consigo nuevos desafíos, que deben ser discutidos y superados, a través de acciones que garanticen el apoyo a los agricultores, con el objetivo de reducir los efectos de la pandemia.

Palabras clave: Agricultura familiar; Alimentación escolar; COVID-19.

\section{Introdução}

Devido ao isolamento social provocado pela pandemia da COVID-19, e com a suspensão das atividades escolares, os gestores do PNAE tem encontrado grandes dificuldades para executar e garantir o fornecimento da alimentação escolar (AE). Com a paralisação das aulas, muitos alunos ficaram impedidos de terem acesso à alimentação escolar, e a população estudantil não foi a única que sofreu prejuízos, classes como os agricultores familiares (AF), responsáveis pelo fornecimento de produtos in natura para a $\mathrm{AE}$ foram diretamente atingidos.

Diante da atual conjuntura, inicialmente os gestores se viram impossibilitados de adotarem medidas para evitar que o fornecimento da alimentação fosse suspenso, devido à legalidade que ampara a utilização dos recursos do PNAE. Nesse sentido, a Lei n. 13.987 autorizou, "em caráter excepcional, durante o período de suspensão das aulas em razão de emergência ou calamidade pública, a distribuição de gêneros alimentícios adquiridos com recursos do PNAE aos pais ou responsáveis dos estudantes das escolas públicas da educação básica".

Os gestores passaram a distribuir os itens da alimentação escolar por meio de kits, e os mesmos, na maioria dos casos, são compostos por alimentos perecíveis, para facilitar a distribuição, surgindo dificuldades na aquisição e manutenção da compra dos alimentos da AF.

O FNDE preconizou na Cartilha com Orientações do PNAE que, durante a pandemia aponta alternativas para dar continuidade à alimentação escolar, como a elaboração da chamada pública eletrônica e a manutenção dos contratos firmados com os agricultores familiares, para que o agricultor não sofra prejuízos.

Ressaltasse ainda que, apesar da promulgação em caráter excepcional da Lei n ${ }^{\circ} 11.947 / 2009$, esta não revogou a obrigatoriedade da destinação de 30\% dos recursos para a compra da agricultura familiar, uma legislação que já era difícil de ser cumprida. Com a pandemia e suspensão das aulas, a situação ficou ainda mais delicada.

O objetivo desse estudo é discutir os desafios para execução do PNAE em relação à compra da agricultura familiar durante a pandemia pela Covid-19. De forma específica, analisamos o impacto em 4 cidades do Estado do Piauí. Para atingir os objetivos do estudo, foi realizada uma pesquisa bibliográfica com base em fontes documentais e bibliográficas, bem como a aplicação de questionários com os gestores das cidades em estudo.

\section{Considerações Gerais Sobre Agricultura Familiar}

A agricultura familiar é aspecto que merece destaque quanto se trata de alimentação escolar. A agricultura é o conjunto de técnicas utilizadas para cultivar plantas com o objetivo de obter alimentos, fibras, energia, matéria-prima para roupas, dentre outros (Lima Silva \& Iwata, 2019)

No Brasil, mais de $80 \%$ das explorações agrícolas são do tipo familiar, e esse cenário brasileiro admite que o país se destaque como a $8^{\mathrm{a}}$ maior produtora de alimentos no mundo nesse segmento (SEAD, 2018).

No Brasil, os agricultores familiares já receberam diferentes nomenclaturas, tais como: roceiro e caipira. Esses indivíduos vivem no campo e são responsáveis pela produção agrícola do país. 
Atualmente, para definir a agricultura familiar, utiliza-se a definição da Lei n ${ }^{\circ} 11.326$, de 24 de julho de 2006 que, em seu art. $3^{\circ}$, considera agricultor familiar e empreendedor familiar rural aquele que pratica atividades no meio rural, atendendo, simultaneamente, aos seguintes requisitos: não deter qualquer título de área maior do que 4 (quatro) módulos fiscais; utilizar a mão de obra da própria família nas atividades econômicas; ter renda familiar originada de atividades econômicas vinculadas ao próprio estabelecimento e dirigir seu estabelecimento ou empreendimento com sua família.

Cabe apontar que os requisitos, de acordo com a lei em análise, são cumulativos. Portanto, deve o sujeito cumular tais condições. Em síntese, a família, ao mesmo tempo em que é proprietária dos meios de produção, assume o trabalho no estabelecimento produtivo. A agricultura familiar contribui com diversos alimentos para a nutrição dos brasileiros.

A origem da nossa agricultura familiar tem como referências cinco "grupos": os índios (os primeiros fornecedores de alimentos para os colonizadores portugueses); os escravos africanos (produção de gêneros alimentícios feita por escravos negros); os mestiços (campesinato no período colonial, formadas por filhos bastardos dos senhores de engenho, sem direito a herança, grande parte, viviam da agricultura, fornecendo alimentos para os engenhos e para as vilas) e os imigrantes europeus (que recebiam lotes doados pelo governo, que também custeava a viagem deles ao Brasil e pagava pelos primeiros implementos agrícolas) (Altafin, 2007).

$\mathrm{O}$ autor supramencionado ressalta ainda que, apesar desses grupos serem diferentes, os mesmos estão interligados pela posição secundária dentro da sociedade brasileira desde sua origem, pois no país as grandes propriedades que cultuam a monocultura de exportação recebiam estímulos e garantias do Estado, e os camponeses ligados aos cultivos alimentares dirigidos ao abastecimento interno eram colocados à margem das políticas públicas.

A agricultura familiar é a principal forma de produção agrícola de diversas cidades brasileiras e constitui uma estratégia de desenvolvimento econômico, social, cultural e sustentável e deve ser valorizada e ter políticas públicas voltadas para a sua ascensão.

Nessa acepção, uma importante política de afirmação da agricultura familiar do Estado foi a promulgação da Lei no. 11.947/2009 pelo FNDE, quando o PNAE passou a exigir que, no mínimo, 30\% dos recursos repassados para estados e municípios devem serem destinados à compra direta de alimentos provenientes da agricultura familiar, uma alteração importante que favoreceu a conexão entre a agricultura familiar e a alimentação escolar e tem o objetivo de melhorar a qualidade dos cardápios escolares, uma vez que incentiva o consumo de alimentos saudáveis.

A introdução de gêneros alimentícios derivadas da agricultura familiar possibilita aos municípios utilizar alimentos mais saudáveis e orgânicos. O intuito é aumentar a qualidade das refeições servidas, possibilitando o desenvolvimento da agricultura familiar e incentivo à economia local (Chaves et al., 2009).

Mesmo diante da exigência legal, muitos municípios não conseguem atingir o percentual mínimo de alimentos exigidos na lei, o que pode gerar consequências severas conforme o artigo 37 da Resolução CD/FNDE n 38 , de 16 de julho de 2009 (Brasil, 2009), na qual preconiza que o FNDE suspenderá o repasse dos recursos financeiros à conta do PNAE quando a Entidade Executora (município) não aplicar os recursos em conformidade com os critérios estabelecidos e, caso ocorra a suspensão, os alunos podem ficar sem a alimentação escolar.

Um estudo realizado no ano de 2012 nos 5.565 municípios brasileiros quanto à compra de alimentos da agricultura familiar pelo PNAE, concluiu que 78,5\% dos municípios brasileiros adquiriam alimentos da agricultura familiar, destacando-se a região Sul, com a maior frequência (95,5\%), e a região Centro-Oeste com a menor (67,9\%) (Machado et al., 2018).

De maneira específica, em relação aos estados da região Nordeste, o Piauí possuía a menor frequência (55,0\%), seguido por Alagoas com (60,7\%). O estado como maior evidência foi o Ceará, com $(91,8 \%)$. Esse mesmo estudo indicou ainda que municípios de grande porte, com gestão do tipo mista, descentralizada ou terceirizada e sem nutricionista 
apresentaram menor frequência de compra de alimentos da agricultura familiar, em relação aos municípios com gestão centralizada e de menor (Machado et al., 2018).

O Nordeste é a região brasileira que detém a maior parcela dos estabelecimentos agrícolas familiares do país comparado com as demais regiões. Porém, o Piauí é uma das regiões do Nordeste mais castigada pela seca e com dificuldades no desenvolvimento da agricultura familiar. E esse contexto gera dificuldades da inserção de gêneros alimentícios provenientes da agricultura familiar no cardápio das escolas.

\section{Dificuldades Encontradas Agricultor para Participação no PNAE}

Pesquisas sobre agricultura familiar e alimentação escolar têm verificado dificuldades para o agricultor acessar e permanecer neste mercado. Estes problemas estão relacionados a questões operacionais, estruturais, políticas, organização dos agricultores, dificuldade de logística, a falta de formação e informação, a falta de documentação dos agricultores, a desconfiança dos mesmos em relação ao poder público, a informalidade das agroindústrias, a falta de articulação entre os gestores e os agricultores e celeumas políticas (Baccarin et al., 2017)

Em uma pesquisa realizada no Sul do Estado do Piauí sobre a aquisição de produtos da AF pelas escolas, demonstrou-se que as principais dificuldades encontradas, tanto pelos órgãos municipais como pelos produtores foram: quantidade insuficiente de gênero alimentício para a demanda solicitada, falta de interesse dos agricultores, a dificuldade em apresentar a documentação exigida pelo programa, problemas burocráticos na administração municipal, ausência de informação dos agricultores em relação ao PNAE, falta de condições estruturais dos agricultores em distribuir seus produtos (Gomes \& Amorim, 2018).

São inúmeros os entraves enfrentados pelos agricultores para participar do processo de venda dos alimentos escolares, sendo a maioria relacionada à falta de informação sobre o funcionamento PNAE, que gera o desinteresse ou a falta de confiança dos agricultores no poder público, devido à cultura de pagamentos atrasados e preços abaixo do valor de mercado.

A situação econômica precária dos agricultores limita suas atividades a se voltar apenas para a sua própria subsistência. Assim, a quantidade de gêneros alimentícios para as demandas solicitadas pelas escolas é escassa, sendo os alimentos produzidos insuficientes e pouco diversificados para abastecer as escolas do município.

No que tange à falta de interesse dos agricultores em participar do processo, na maioria dos casos, essas famílias não têm intenção de substituir atividades de subsistência por atividades comerciais, mesmo as que têm conhecimento da potencialidade financeira dessa ação. Esse risco é aumentado pelo baixo conhecimento gerencial que os agricultores possuem (Breitenbach, 2018).

Dentre os entraves apontados, um que merece destaque é a complexidade e burocratização da legislação brasileira em relação à documentação exigida para o agricultor participar dos processos licitatórios, uma vez que essa população é carente e não possui a documentação exigida pelo programa, o que pode ser gerado pela falta de informação e políticas de conscientização e divulgação da importância, forma de participação e funcionamento do programa.

As formas de gestão mais utilizadas no Brasil são a centralizada ou descentralizada, nas quais as compras devem ser precedidas de licitação. A Resolução do FNDE nº 38 de 2009, primeira regulamentação da Lei nº 11.947 de 2009, determina que, frente à dispensa licitatória, utilize-se a chamada pública $(\mathrm{CP})$ como instrumento para aquisição dos produtos da agricultura familiar, devendo garantir preços mais justos aos agricultores familiares, dando prioridade no certame aos agricultores locais (do município). Na impossibilidade disso, a prioridade será para agricultores do território rural, seguidos por agricultores do estado e, por fim, caso necessário, por agricultores de outros estados 
O Quadro 1 ilustra a quantidade e a complexidade de documentos exigidos aos agricultores para habilitação e consequente participação da Chamada Pública da AE. A lista de exigências não é simples para um indivíduo que, na grande maioria dos casos, não possui instrução e informação para realizar o levantamento da documentação exigida. Vejamos:

Quadro 1 - Documentação exigida aos produtores da Agricultura Familiar para participação no PNAE.

\begin{tabular}{|c|c|}
\hline GRUPOS FORMAIS & $\begin{array}{l}\text { - Prova de inscrição no Cadastro Nacional de Pessoa Jurídica - CNPJ; } \\
\text { - Extrato da Declaração de Aptidão ao Pronaf (DAP jurídica) para associações e } \\
\text { cooperativas, emitido nos últimos } 60 \text { dias; } \\
\text { - Prova de regularidade com a Fazenda Federal, relativa à Seguridade Social e ao Fundo de } \\
\text { Garantia por Tempo de Serviço - FGTS; } \\
\text { - Cópias do estatuto e ata de posse da atual diretoria da entidade registrada no órgão } \\
\text { competente; } \\
\text { - Projeto de venda assinado pelo seu representante legal; } \\
\text { - Declaração de que os gêneros alimentícios a serem entregues são produzidos pelos } \\
\text { associados/cooperados; } \\
\text { - Declaração do seu representante legal de responsabilidade pelo controle do atendimento } \\
\text { do limite individual de venda de seus cooperados/associados; } \\
\text { - Prova de atendimento de requisitos previstos em lei específica, quando for o caso. }\end{array}$ \\
\hline GRUPOS INFORMAIS & $\begin{array}{l}\text { - Prova de inscrição no Cadastro de Pessoa Física - CPF; } \\
\text { - Extrato da Declaração de Aptidão ao Pronaf (DAP física) de cada agricultor familiar } \\
\text { participante, emitido nos últimos } 60 \text { dias; } \\
\text { - Projeto de venda com assinatura de todos os agricultores participantes; } \\
\text { - Declaração de que os gêneros alimentícios a serem entregues são produzidos pelos agricultores } \\
\text { familiares relacionados no projeto de venda; } \\
\text { - Prova de atendimento de requisitos previstos em lei específica, quando for o caso. }\end{array}$ \\
\hline $\begin{array}{lr}\text { FORNECEDOR } \\
\text { INDIVIDUAL } \\
\text { (DETENTOR DE DAP } \\
\text { FÍSICA E } & \text { NÃO } \\
\text { ORGANIZADO } & \text { EM } \\
\text { GRUPO) } & \end{array}$ & $\begin{array}{l}\text { - Prova de inscrição no Cadastro de Pessoa Física - CPF; } \\
\text { - Extrato da Declaração de Aptidão ao Pronaf (DAP física) do agricultor familiar participante, } \\
\text { emitido nos últimos } 60 \text { dias; } \\
\text { - Projeto de venda com a assinatura do agricultor participante; } \\
\text { - Declaração de que os gêneros alimentícios a serem entregues são oriundos de produção própria, } \\
\text { relacionada no projeto de venda; } \\
\text { - Prova de atendimento de requisitos previstos em lei específica, quando for o caso. }\end{array}$ \\
\hline
\end{tabular}

Fonte: FNDE (2016).

Tais exigências documentais para habilitação no PNAE dificultam ou até mesmo impossibilitam a participação dos agricultores na venda da AE. Faltam em muitos casos até mesmo as documentações mais básicas exigidas do trabalhador rural, como Declaração de Aptidão ao Pronaf (DAP), documento de identificação do agricultor familiar, utilizado para o acesso às políticas públicas.

A falta de documentações essenciais para participar da alimentação escolar, sobressalta uma fragilidade muito grande dentro desse contexto, pois muitos não possuem a documentação necessária para atender a todas as Chamadas Públicas de Compras (CPC), das Secretarias de Educação Estaduais (SEEs) e das Secretarias Municipais de Educação (SMEs) (Gomes \& Amorim, 2018).

Com o objetivo de propagar as informações passo-a-passo relativo à aquisição desses produtos, a Coordenação Geral do Programa Nacional de Alimentação Escolar - CGPAE/FNDE elaborou o Manual de Aquisição de Produtos da Agricultura Familiar para a Alimentação Escolar.

Sobre esse aspecto, o Manual de Aquisição de Produtos da Agricultura Familiar para a Alimentação Escolar destaca 10 passos aquisição de produtos da agricultura familiar para a alimentação escolar: 1) Orçamento; 2) Articulação entre os atores sociais; 3) Cardápio; 4) Pesquisa de preço; 5) Chamada pública; 6) Elaboração do projeto de venda; 7) Recebimento e seleção dos projetos de venda; 8) Amostra para controle de qualidade; 9) Contrato de compra; 10) Termo de recebimento e pagamento dos agricultores (FNDE, 2016). 
Cada passo possui uma especificidade e um responsável pela sua execução. Os passos devem ser seguidos para o desenvolvimento eficaz do processo. O Quadro 2 descreve de maneira didática essas fases.

Quadro 2 - Passos aquisição de produtos da agricultura familiar para a alimentação escolar.

\begin{tabular}{|c|c|c|}
\hline ETAPA & OBJETIVO & RESPONSÁVEL \\
\hline ORÇAMENTO & $\begin{array}{c}\text { Levantar os recursos orçamentários } \\
\text { disponíveis; }\end{array}$ & Entidade Executora \\
\hline $\begin{array}{c}\text { ARTICULAÇÃO ENTRE OS ATORES } \\
\text { SOCIAIS }\end{array}$ & $\begin{array}{c}\text { Mapear a diversidade e a quantidade os } \\
\text { produtos da agricultura ofertados pela } \\
\text { agricultura familiar; }\end{array}$ & Entidade Executora (com parceiros) \\
\hline CARDÁPIO & $\begin{array}{l}\text { Planejar um cardápio nutritivo, baseado na } \\
\text { agricultura familiar, respeitando a cultura e a } \\
\text { vocação agrícola local; }\end{array}$ & Nutricionista (responsável técnico) \\
\hline PESQUISA DE PREÇO & $\begin{array}{l}\text { Definir previamente os preços na publicação } \\
\text { no edital da Chamada Pública. Devem refletir } \\
\text { os preços de mercado; }\end{array}$ & Entidade Executora (e parceiros \\
\hline CHAMADA PÚBLICA & $\begin{array}{c}\text { Tornar pública a intenção de compra dos } \\
\text { produtos da agricultura familiar para a } \\
\text { alimentação escolar. Deve ser dada ampla } \\
\text { publicidade; }\end{array}$ & Entidade Executora \\
\hline $\begin{array}{c}\text { ELABORAÇÃO DO PROJETO DE } \\
\text { VENDA }\end{array}$ & $\begin{array}{c}\text { Apresentar a proposta de fornecimento de } \\
\text { gêneros alimentícios (variedade, quantidade, } \\
\text { cronograma de entrega), de acordo com o } \\
\text { publicado na Chamada Pública, e conforme a } \\
\text { possibilidade de atendimento de cada } \\
\text { fornecedor; }\end{array}$ & $\begin{array}{l}\text { Agricultores familiares, ou suas associações } \\
\text { ou cooperativas }\end{array}$ \\
\hline $\begin{array}{l}\text { RECEBIMENTO E SELEÇÃO DOS } \\
\text { PROJETOS DE VENDA } \\
\end{array}$ & $\begin{array}{l}\text { Habilitar dos projetos de venda. Averiguar a } \\
\text { documentação dos fornecedores; }\end{array}$ & Entidade Executora \\
\hline $\begin{array}{c}\text { AMOSTRA PARA CONTROLE DE } \\
\text { QUALIDADE }\end{array}$ & $\begin{array}{l}\text { Avaliar se os produtos possuem: a) } \\
\text { especificações da Chamada Pública; b) } \\
\text { certificação sanitária, quando houver essa } \\
\text { exigência; c) atender ao teste de amostra, }\end{array}$ & Entidade Executora \\
\hline CONTRATO DE COMPRA & Celebrar os contratos com a EEX. & Entidade Executora e fornecedores \\
\hline $\begin{array}{c}\text { ENTREGA DOS PRODUTOS, TERMO } \\
\text { DE RECEBIMENTO E PAGAMENTO } \\
\text { DOS AGRICULTORES }\end{array}$ & $\begin{array}{l}\text { Entrega dos produtos e recebimento do } \\
\text { pagamento pelos insumos fornecidos. }\end{array}$ & Entidade Executora e fornecedores \\
\hline
\end{tabular}

Fonte: FNDE (2016).

Frisa-se também outro grande desafio que essa categoria enfrenta, que é a falta de condições estruturais em distribuir seus produtos, tais como a falta de infraestrutura para a produção, o armazenamento e a distribuição até o mercado consumidor. Os municípios exigem que os agricultores transportem os alimentos comprados até as escolas.

Apesar da ampla efetivação da aquisição de alimentos da agricultura familiar pelo programa em todo país, nota-se nas pesquisas sobre o assunto que os municípios não conseguem cumprir o mínimo exigido em lei, demandando mais ações educativas e assistência técnica direcionadas à agricultura familiar.

\section{Metodologia}

Inicialmente, para levantamento de dados bibliográficos, foi realizada uma revisão bibliográfica, no Google acadêmico, Scielo e Web of Science, abrangendo textos publicados entre março de 2020 a fevereiro de 2021, tendo como palavras descritoras: agricultura familiar, alimentação escolar e a pandemia de Covid-19.

Além da revisão bibliográfica sobre a temática da agricultura familiar e a pandemia do COVID-19, houve um estudo de caso de 4 municípios piauienses com a coleta de dados baseadas em análise documental e aplicação de questionários sobre o cumprimento da Lei $\mathrm{n}^{\circ}$ 11.947/2009 pelo FNDE, através da qual o PNAE passou a exigir que no mínimo 30\% dos recursos repassados para estados e municípios deveriam ser destinados à compra direta de alimentos provenientes da agricultura familiar durante a pandemia. 
A coleta de dados foi realizada através do questionário, enviado via Google Forms para os gestores responsáveis pela AE nos 4 municípios, com 3 perguntas: 1- Houve cumprimento da exigência da compra dos 30\% da Agricultura Familiar? 2Os kits fornecidos possuem frutas e hortaliças in natura e a aquisição de gêneros alimentícios da agricultura familiar? E 3- O processo de compra da agricultura familiar por meio de chamada pública poderá ser realizado por procedimentos de maneira remota, não presencial, com ferramentas, modos e meios on-line?

Para garantir o anonimato dos dados informados pelos gestores municipais, denominaremos os municípios com as consoantes: A, B, C e D, a saber pelas características mostradas no Quadro 3.

Quadro 3 - Informações municípios do estudo.

\begin{tabular}{|c|c|c|c|c|}
\hline \multicolumn{2}{|c|}{$\begin{array}{c}\text { População } \\
\text { estimada 2020 }\end{array}$} & $\begin{array}{c}\text { Taxa de } \\
\text { escolarização de 6 a } \\
\text { 14 anos de idade }\end{array}$ & $\begin{array}{c}\text { Estudantes } \\
\text { atendidos pelo } \\
\text { PNAE }\end{array}$ & $\begin{array}{c}\text { Estudantes que } \\
\text { receberam kits na } \\
\text { pandemia }\end{array}$ \\
\hline A & 63.787 pessoas & $97,3 \%$ & 10.942 alunos & 10.800 alunos \\
\hline B & 28.874 pessoas & $94,8 \%$ & 2.746 alunos & 2.200 alunos \\
\hline C & 8.347 pessoas & $96,7 \%$ & 1.005 alunos & 5.815 alunos \\
\hline D & 4.354 pessoas & $95,8 \%$ & 431 alunos & 600 alunos \\
\hline
\end{tabular}

Fontes: IBGE (2021) e FNDE (2021).

As cidades em estudo beneficiam juntas 15.124 estudantes diariamente antes da pandemia. Com a paralisação das aulas devido ao COVID-19, observa-se que o número de beneficiados diminuiu, um reflexo negativo causado pela pandemia, tirando dos beneficiários da $\mathrm{AE}$ o seu direito à alimentação.

\section{Agricultura Familiar e Pandemia de COVID-19}

Conforme descrito na seção anterior, são muitos os entraves burocráticos que inviabilizam a participação efetiva e venda da agricultura familiar para a AE. No entanto, no ano de 2020, um fato superveniente piorou ainda mais a situação dos agricultores, a suspensão das atividades nas escolas.

Tal contexto pandêmico fez com que as aulas dos municípios atendidos fossem suspensas e com isso também foram interrompidas as atividades do PNAE na escola, pois com a suspensão imediata das aulas acabou as compras dos insumos para o preparo das merendas, repercutindo negativamente sobre os sistemas de abastecimento alimentares locais e sobretudo da agricultura familiar.

Em pesquisa realizada por meio de aplicação de questionário on-line com gestores da AE de 4 municípios, procurouse investigar se houve a realização de chamada pública para venda de alimentos da AF durante o período em que as aulas estavam suspensas, bem como se o município conseguiu cumprir a exigência da Lei no 11.947/2009 de destinação de no mínimo 30\% dos recursos na compra direta de alimentos provenientes da agricultura familiar (Quadro 4).

Quadro 4 - Dados do estudo sobre a Agricultura Familiar e Alimentação Escolar.

\begin{tabular}{|c|c|c|c|}
\multicolumn{1}{|c}{} & \multicolumn{1}{c}{$\begin{array}{c}\text { Houve chamada } \\
\text { Mública remota }\end{array}$} & $\begin{array}{c}\text { Cumpriu a compra de 30\% } \\
\text { AF }\end{array}$ & $\begin{array}{c}\text { Composição dos kits possui } \\
\text { alimentos da AF }\end{array}$ \\
\hline A & SIM & NÃO & NÃO \\
\hline B & NÃO & NÃO & NÃO \\
\hline C & SIM & NÃO \\
\hline D & SIM & SIM & SIM \\
\hline
\end{tabular}

Fonte: Autores (2021). 
Podemos observar que, de acordo com os dados coletados no estudo no quesito 1, quando questionados se houve chamada pública os municípios A, C e D responderam que sim e o B respondeu que não. Cabe ressaltar que no questionário possuía uma questão subjetiva para que os sujeitos do estudo relatassem algum ponto que merecia destaque. Nesse sentido, a gestor do município $\mathrm{C}$ destacou:

"O não cumprimento da aquisição de $30 \%$ de produtos oriundos da agricultura familiar, considerando que fora realizada chamada pública e não compareceu nenhum interessado. Ademais, a própria logística da distribuição de produtos oriundos da agricultura familiar, considerando a dificuldade de distribuição de produtos facilmente perecíveis" (Gestor do município C).

A fala do gestor reforça uma das dificuldades já apontadas nesse estudo, uma vez que o não comparecimento na chamada pública pode ter sido causada pela falta de documentações essenciais que os habilitam e o atestam a participação do processo ou até mesmo a falta de orientação sobre os procedimentos de forma remota, não presencial e ferramentas on-line.

Outro ponto negativo que pode ser repercutido na fala do sujeito é a precariedade na logística da distribuição de produtos oriundos da agricultura familiar, considerando a dificuldade de distribuição de produtos facilmente perecíveis.

Sobre o cumprimento da Lei $\mathrm{n}^{\circ} 11.947 / 2009$ e sobre a presença de frutas e hortaliças nos kits distribuídos, apenas o município D conseguiu cumprir os tais requisitos de maneira efetiva.

Em estudo realizado, Amorim, Junior e Bandini (2020) destacam como medidas para diminuir os impactos da pandemia nas vendas a AF para alimentação escolar: [...] melhoria da estrutura logística de apoio a essas compras (transporte, beneficiamento e armazenamento), promoção de assistência técnica continuada."

Conforme apontam os estudiosos, há a necessidade de apoio à logística e apoio técnico que forneçam subsídios e conhecimentos necessários para que esses produtores estejam habilitados e preparados para participar das chamadas públicas e consequente venda e entrega dos produtos.

\section{Considerações Finais}

A pandemia de COVID-19 afetou a sociedade significativamente em todos os países do mundo, atingindo alguns setores mais que outros. É o caso dos indivíduos que sobrevivem da agricultura familiar.

De maneira geral, pode-se constatar que a comercialização dos produtos da agricultura familiar, que tinha como principal clientela as escolas, foi fatalmente afetado, havendo perdas econômicas expressivas, uma triste realidade econômica, tendo em vista que essas famílias ou grupos são vulneráveis e não possuem outras rendas a não ser a gerada pelas vendas de seus produtos.

Como principal alternativa apontada para o problema em estudo é habilitar e preparar os agricultores para participar das chamadas públicas bem como garantir a logística da venda e distribuição dos alimentos na alimentação escolar, mesmo em tempos de pandemia.

\section{Referências}

Altafin, I. (2007). Reflexões sobre o conceito de agricultura familiar Texto trabalhado durante o $3^{\circ}$ Módulo do Curso Regional de Formação Político-sindical da região Nordeste. http://www.enfoc.org.br/system/arquivos/documentos/70/f1282reflexoes-sobre-o-conceito-de-agricultura-familiar---iara-altafin---2007.pdf

Amorim, A. L. B., et al (2020). Programa Nacional de Alimentação Escolar: estratégias para enfrentar a insegurança alimentar durante e após a COVID-19. Revista de Administração Pública, 54(4), 1134-1145. https://doi.org/10.1590/0034-761220200349 
Research, Society and Development, v. 10, n. 4, e13910413911, 2021

(CC BY 4.0) | ISSN 2525-3409 | DOI: http://dx.doi.org/10.33448/rsd-v10i4.13911

Brasil. Ministério da Educação. Fundo Nacional de desenvolvimento da educação. Resolução/CD/FNDE N³3, de 16 de julho de 2009 , 2009. https://www.fnde.gov.br/index.php/acesso-a-informacao/institucional/legislacao/item/3341-resolu\%C3\%A7\%C3\%A3o-cd-fnde-n\%C2\%BA-38-de-16-dejulho-de-2009.

Brasil. Lei no 11.346, de 15 de setembro de 2006. http://www.planalto.gov.br/ccivil_03/_Ato2004-2006/2006/Lei/L11346.htm.

Brasil. Lei no 11.947, de 16 de junho de 2009. http://www.planalto.gov.br/ccivil_03/_Ato2007-2010/2009/Lei/L11947.htm.

Breitenbach, R. (2018). Participação econômica das atividades de subsistência na agricultura familiar. Redes, 23(1), 53-68. https://doi.org/10.17058/redes.v23i1.6780

Chaves, L.G. O programa nacional de alimentação escolar como promotor de hábitos alimentares regionais. Revista de Nutrição, 22(6), 857-866, 2009.

Gomes, S. A. B., \& Amorim, L. B. de. (2019). Agricultura Familiar: importância e dificuldades da inserção na alimentação escolar na microrregião de Picos PI. PesquisAgro, 1(1), 39-48. https://doi.org/10.33912/AGRO.2596-0644.2018.v1.n1.p39-48.id253

Lima, A. F., Silva, E. G. de A., \& Iwata, B. de F. (2019). Agriculturas e agricultura familiar no Brasil: uma revisão de literatura. Retratos De Assentamentos, 22(1), 50-68. https://doi.org/10.25059/2527-2594/retratosdeassentamentos/2019.v22i1.332

Machado, P. M. de O. et al (2015). Conselhos de Alimentação Escolar em Santa Catarina, Brasil: uma análise do Discurso do Sujeito Coletivo. Revista de Nutrição, 28(3), 305-317. https://dx.doi.org/10.1590/1415-52732015000300007

Silva, D. S. da C., Santos, M. B. dos, \& Soares, M. J. N. (2020). Impactos causados pela COVID-19: um estudo preliminar. Revista Brasileira De Educação Ambiental (RevBEA), 15(4), 128-147. https://doi.org/10.34024/revbea.2020.v15.10722 